\title{
Some Aspects of Application of Software Agents in Information Retrieval in Virtual- Based Educational Environments
}

\author{
Boyka Gradinarova', Teodora Bakardjieva ${ }^{2}$, Milena Gradinarova ${ }^{3}$ \\ 1 Technical University of Varna Affiliation, 1,Studentska Str., 9010Varna, \\ inflot@mbox.digsys.bg, \\ 2 Varna Free University, 9007 Varna, Golden Sands, Bulgaria, \\ bakardjieva@vfu.bg \\ 3 Sofia University, 15, Car Osvoboditel bul.,1504 Sofia, mimeto@eol.com
}

\begin{abstract}
The problem of information retrieval has attracted increasing attention in recent years. The amount of information sources via networks has grown and is still rapidly growing. Although existing search engines provide rapid retrieval systems, they give limited assistance to consumers in finding the relevant information they need. Intelligent software agents prove to be the necessary tool in improving the effectiveness and efficiency of retrieval. The paper presents concepts about software agents and discusses their advantages in optimizing the retrieval process. This study explores the application of software agents in information retrieval processes in web-based applications for online learning systems. The research was done at Technical University of Varna, and an interactive system new for Bulgaria is proposed.
\end{abstract}

\section{Introduction}

Internet technologies and software agents are becoming increasingly important in online learning systems [4]. Web-based training and the use of agents offer the opportunities to enhance traditional courses, encourage life-long learning and enable more people to join the learning society.

Software agents prove to be the necessary tool in improving the effectiveness and efficiency of retrieval in these systems. Software agents give much promise, especially their ability to improve and intensify collaboration amongst distributed systems. Agents collaborate in a dynamic environment and interact from different sources in Internet-based systems [6]. There must be a defined model for communication concerning all jointly-working agents. In order to standardize a

Please use the following format when citing this chapter:

Gradinarova, B., Bakardjieva, T., Gradinarova, M., 2006, in Intemational Federation for Information Processing, Volume 210 , Education for the $21^{\text {st }}$ Century-Impact of ICT and Digital Resources, eds. D. Kumar, and Turner J., (Boston: Springer), pp. 315-319. 
model many proofs of its characteristics and suitability for different software agents are needed. This summary overview is directed specifically in the area of retrieval in web-based learning applications.

\section{Goal of the observation}

In this paper software agents find application in the retrieving process in virtual educational system. The search criteria are: number of times a keywords appears, proximity of the keywords to each other and proximity of the keywords to the beginning of the document. As with search engines on the web, online databases have problems with their retrieval mechanism, such as finding appropriate subject keywords, a large number of hits along with failure to reduce the retrieval sets, zero hits and failure to increase the retrieval sets, and failure to understand the cataloging rules. For locating matching terms and phrases, online retrieval systems are quite powerful. Processing enormous amounts of documents would be extremely costly, and therefore developing better search techniques provides a realistic solution to the existing problems.

Technical University of Varna is beginning to develop a package of software tools for supporting processes of development of such virtual environments for education. These tools also help agent construction for information retrieval.

This paper proposes a system based on software agents for improving information retrieval performance. The outlined objectives are:

- to develop a methodology for agent learning of user preferences in every user session. The agent will make its own base on the user's preferences and the information content of the queries and the documents.

- to integrate an information retrieval algorithm, a user preference algorithm, an existing search and an agent.

A great amount of work has gone into the modeling of agents but currently available techniques are not so perfect as to produce human-like interactions on a very high level.

There are three basic concepts for building agents [9]. The first approach in building agents consists of making the agent an integrated part of the end program. Its advantage is that the user trusts the agent because the rules are determined. The problem here is with the competence. The agent must be employed effectively by the user, so the user must have enough knowledge. In the second approach, "knowledge-based", the agent has extensive domain-specific information about the application. Here, again competence is a problem because this approach has big requirements on the knowledge of the engineer.

\section{Procedures and methodology}

The goal of the present research is using this approach to create a methodology for agent learning. During the tests of the investigation at the start, the agent is equipped 
with a basic knowledge background and later on it passes through an "educational" process while working for the user.

The procedures of learning require "rehearsal" actions from the agent. So, the use of the application includes cyclic and reiterative steps leading to repetitive behavior. These regularities are potentially different for different users.

With every experience the agent gradually develops its abilities within the actions of the user or among users. The learning approach adopted allows the agent to explain its behavior in a way with which the user is familiar, namely in terms of past situations similar to the current situation..

During the investigation the learning approach proved its advantages over the above mentioned two approaches. It doesn't require a lot of work from the end-user and application developer. The agent adaptation to the user can be done more easily. So this approach facilitates and helps in transferring information and know-how among the different users of a community.

The system allows total monitoring of the teaching and learning process. The instruments make possible views of the syllabuses, study schedules, academic calendar and other useful information for teachers and students. Also there are a library and a search tool. Organized forums give possibility for discussions. Teachers have at their disposal modules for creating courses and tests. The advantage is the acceptation of different formats in which the course material is produced. The system works also in an intranet.

\section{Results and discussion}

The main results from the application of agents in retrieving processes in the online learning system can be described in the following aspects:

- All students use an agent for searching information databases on the web for new information of relevance. The agent is educated by feeding with new keywords. This results in an ever-changing library of articles of interest to students of the field, which the students can access also after having left the university;

- Agents working through the students' web-browsers are also implemented. They work in several ways. Some are based on searching the Internet through, e.g., Google, and found documents are marked as "of value" or "of no value" by the students. The agent keeps this in mind and sorts the documents. The agent tracks the most often visited web sites from each student and retrieves the latest update for these web pages, so that it becomes possible for each student to read them every day without waiting for them to be downloaded from the Internet. Also, at all times the agent analyses the contents of the web page the student is reading and makes a list of other similar pages for the user to read after finishing the present page.

- E-mail agents are introduced for the e-mail application. In the previous years all information for all students was sent to large groups and then the students had to find the e-mails they needed. At the present, it's only necessary for the students to tell to the agents what information they are interested in, so that the agents can select the needed e-mails. Also, the agents look at the pattern of how the 
students read their e-mail from their families and friends and sort the mail according to these points of interest.

The agent keeps all actions the user performs for a certain period of time. The agent analyzes the action log and it makes a search for patterns of behaviour. When the agent finds such patterns it will offer to automate them for the user.

The functions of the agents are different but they are all coordinated through the user interface agent, so that the student experiences interaction with a single agent. A user can create one or many agents and train them by means of examples of articles that should or should not be selected. The agents can be divided according to the field- business, computer studies, management, etc.

An agent is initialized by giving it some positive and negative examples of articles to be retrieved. Full-text analyses are used by the agent to retrieve the words in the text that may be relevant. It remembers the structured information about the article, such as the author, source, assignation, etc. The user can program the agent by completing some templates of articles that should be selected.

\section{Evaluation of the system by users}

In order to define and check the users' opinions on the system an inquiry has been carried out among them. It reveals approval of the applications. Even while testing the system the students show growing interest and motivation for learning, and higher results in the examination procedures. In the feedback some remarks and recommendations have been made by the users and during the trial period they are tested.

Users enjoy working with the system and find it very useful. The basic restriction given from the system is that it is limited to keywords only. In this context, the methods for deeper semantic analysis of texts will optimize the performance of the system and this deeper representation can be learned by using the same statistical learning techniques as are currently used for relevant keywords.

\section{Conclusion}

The software agents that were used gradually learn how to improve in assisting the user and increasing their competency, accumulating knowledge by: observing and imitating the user; receiving positive and negative feedback from the user; and taking instructions from the user and asking other agents for advice.

The agent technology that was used has the capability and potential for optimizing and modernizing learning and teaching processes in Bulgarian universities in the pre-accession stage for the country. A new education system is gaining speed in Bulgaria that is not based only on humans and traditional methods but on intelligent agents providing just-in-time mentored learning.

Future research still needs to be carried out into methodologies for design, implementation and adoption in the field of education, collaborative learning theories, and verification of systems to maintain their stability in performance and 
operation. Aside from the difficulties in actually constructing software agents for education, exploring the development of intelligent agents is worthy in that it helps further our understanding of instruction.

The suggested system is in a period of adoption in the Technical University of Varna, and it is part of an automated information system (AIS) implemented at the university for the aims of university management, covering different aspects of the administrative, scientific and teaching activities. It aims at improving the effectiveness of the work of all units in the university, and the present study contributes in this direction.

Application of software agents is an important step in renewing the educational system in Bulgaria and developing new forms of web-based learning systems, such as distance learning and long-life-learning.

\section{References}

1. Chan, T.W. (1998), The past, present, and future of educational agents http://www.apc.src.ncu.edu.tw/apc/ppt_chan.html

2. Collis, B. and Moonen, J. (2000), Flexible Learning in a Digital World, London, Kogan Page.

3. Croft, D. W.: Intelligent Software Agents: Definitions and Applications. http://www.alumni.caltech.edu/ croft.

4. De Diana, I., Aroyo, L.: Knowledge Management for Networked Learning Environments: Applying Intelligent Agents. [On-line] (Accessed November 2004) http://projects.edte.utwente.nl/proo/italo.htm.

5. Finnie S.: Information Retrieval for Your Intranet, PC Magazine Online http://www8.zdnet.com/pcmag/issues/1609/pcmg0041.htm.

6. Flores, R.A., Kremer, R.C., Norrie, D.H.: An Architecture for Modeling Internet-based Collaborative Agent Systems. Proc. of the Workshop on Infrastructure for Scalable Agents Systems, Fourth International Conference on Autonomous Agents (Agents'2000), T. Wagner and O.F. Rana (Eds.), June 3-7 (2000), Barcelona, Spain. http://www.cpsc.ucalgary.ca/ robertof/publications/ aa00/aa2000w13 FloresKremerNorrie.pdf.

7. Hermans, B.: Intelligent Software Agents - An Inventory of Currently Offered Functionality in the Information Society and a Prediction of Near Future Developments (Accessed October 2004) http://www.firstmonday.dk/issues/ issue 2 3/ch 123/index.html http://www. firstmonday.dk/issues/issue2 3/ ch 45/index.html http://www. firstmonday.dk/issues/issue2 3/ch 67/index.html.

8. Kalawsky, R.: Exploiting Virtual Reality Techniques in Education and Training: Technological Issues (Accessed November 2004) http://www.agocg.ac.uk/reports/virtual/vrtech/title.htm.

9. Maes, P.: Agents that Reduce Work and Information Overload, Communication of the ACM 37 (7), (1994) 31-40. 